\title{
Research on the Application and Choice of Dance Music
}

\author{
Li Chen \\ College of Music,Jiangxi University of Technology
}

Keywords: Music; Dance; Performance; Rhythm; Show; Creation

\begin{abstract}
Dance is a comprehensive art. Dance contains the concept of time, and is also included in the concept of space. In the form of dance performance, many other sister art types are included, which shows their respective characteristics in the dance art. This article studies the relationship between the art of dance and music through the dance art itself .This pair of sister art has inevitable connection in reality, both of which are and mutual assistance and restrict each other. Especially in the dance world, music has a great influence on the development of the dance art, which is both positive and developmental. Because the dance art can't be separated from the music, the demand for music in dance art in number is very large.
\end{abstract}

\section{Introduction}

Dance is the earliest art form of e human action. The factor of the dance contains the factor of music, and music is the basis of the rules of the dance movement. In any kind of dance, any dancer must perform according to the rhythm of the music. Music is like the oxygen in the dance art, so dance in the process of art performance needs musical elements all the time. But this need is ignored by many of the dancers and musicians, thereby reducing the friction among the inspiration of art. The development of dance art is influenced both by the internal factor and external factor. Internal cause is the independent direction of the development of dance art, which is decided and guided by the direction of each subject in dance art; while the outer is controlled by the time which the dance art exists, the political environment and economic conditions of the country. Dance art belongs to the luxury goods of the cultural industry and the most abstract art form in the field of art, whose development must get the support of external factor.

With the change of the times, China's economy develops rapidly and dance culture is a flourishing as never before. The output of Chinese dance works in the world ranks the top. Every year, there are a large number of outstanding dance works including independent and short dance works, dance, poetry and drama, most of the which have different degree of innovation from content to form, then to the appreciation of beauty. A large number of new and excellent, meaning profound works are published in any form. In these dance works, some are the products of market economy, with thematic content and they are produced under support and regulation of economic levers and has certain market value, while others are thematic works singing the praises of the main melody and these dance works are times in the reflection of theme and expression, conforming to outlook on life and world outlook of the contemporary era. That is the dance work bred in various embryos is faced with a common problem -- the lack of source of "dance music". This lack will directly affect the development of dance art and become an obstacle in the development of the dance art.

In dance creation, music is one of the important factors, the emotional contrast of dance and expression of emotion in the dance. The dance becomes an audio-visual art form through the use of 
music. Although the dance can also produce hearing by the human voice, audience receives auditory sensations of rhythm and melody of the music in most cases. Since the birth of the dance, it has been always integrated with music into an art form appearing on the stage. In the process of the creation of dance works and dance teaching, looking for music is a great difficulty for all choreographers and dance educator. Most of the time, in order to search for music of dance, choreographies and dance educators must spend a lot of time and money to compose music suitable for their works. In the dance teaching and dance creation, such a circle brings many difficulties inevitably and affects the development of dance. But so far, there is still no one can solve this problem. The reason is that the combination of these two industries is not very good, leading to awkward situation where there is no music in dance.

The knowledge and experience of human can only come from physical activity of a person. Without this physical activity, we will not understand any perceptual objects. According to Collingwood's theories which takes the initial art as "language", only combined with action ,do any kind of language including painting language, music language and poetry be meaningful, but the action will no to happen as a manifestation of language. So all other artistic forms can only emerge from the parent of the dance art which takes physical activity as the sole prerequisite. This is probably the reason why poetry, music and dance are always trinity in the original art. Therefore, Sachs said, "The puzzling fact is that, as a kind of advanced art, dance has been developed in the early stage."

In the development of the dance, the amount of the creation of the dance works is equivalent to the amount of demand for dance music. How can the dance work have the rhythm and melody of music suit for its connotation. This need dance creators take the initiative to find and musicians to create dance works specially, even so, the number of music which can be used for artistic creation of dance is very few, which has become an indisputable fact. In the present development of dance, people who create specially for the dance art are very rare and the dance art also has not planned its own type of music, which causes people discount dance music and the dance music can not meet the needs of the dance works. Dance teacher and choreographer find the so-called "dance music" which can be used by themselves in the boundless sea of the music. These are not music exclusive to dance, but to any kind of art forms.

There is also a source of dance music, which is created specifically for the dance art.

\section{The production of problem and its significance}

The relationship between dance and music. Dance and music are display in the flow of time, but in the factor of time, music and dance have the same rhythm at the same time, which shows that the dance is the performance in the accompaniment of music.

The subjects of dance music in dance art. Dance teaching(Dance education is the best way a dance teacher convey professional skills to students by the pattern of oral instruction and demonstration. Teaching is the necessary means to cultivate and find a good dancer. There is not lack the accompaniment of music in the dance classroom, which is the emotional sustenance of the dancers, so dance class has larger demand on good and emotional dance music).

Dance performance (The dance performance is the best way to spread dance art to the outside world. Lacking audition appreciation of the music will make observes feel the boredom of physical changes, thus reducing the charm of the dance. The use of music in the dance performance is related to the success of the dance performance. 
Dance creation (Awards for creation, performance and education of the dance art are set in dance competitions ,and dance music are also included. This shows that the dance person has recognized the position if dance music in the dance art, but this has not caught the music person's attention, which is also the reason for the lack of dance music.

The Classification of dance music. According to the use of dance music: training dance music and performing dance music.

According to the time of dance music: the traditional dance music and original dance music.

According to the types of dance: classical dance music, folk dance music, modern dance music and symphonic dance music.

Problems in dance music. 1 . The number of special dance music is less.

2. The identical phenomenon of type of dance music is serious.

3 It is very difficult to achieve the innovation and sweet of dance music at the same time.

4. The creators of the dance music are less, so that the originality of dance music is poor, and the original expense of dance music is high.

5. The dancers and dancers' initiative to explore dance music is lacking, which makes the music in the dance teaching is often relatively outmoded and causes the dancers can not reach the assistant of the music when training.

\section{The significance of dance and music in the integration of Art}

This paper repeatedly emphasizes the important position of music in the dance art, so that the quality and quantity of music can directly contact with the development of dance arts. But the supply of music for the dance is not enough. In order to solve the problem of the relationship between the music and the dance, the first thing is to study the point at which the two kinds of art are the mutual restriction and mutual restriction. Following in this paper is to analysis the position of dance music in the dance through the dance works and study the differences among music to stimulate the discovery, creation and use of dance music.

The lack of dance music is mainly for the creation of the dance, a new dance often need new music, and mostly need the creation special for dance works; While in the dance teaching, the emotional expression and rhythm of music is the key to the application of dance music; the dance music is often connected with the creation of dance and dance education. Therefore, if the first two problems are solved well, the problem of dance music is also solved.

Dance needs the melody of music, more needs the rhythm

Dance needs the cooperation of music. At the moment of the emergency of dance, the music was created immediately, and the two forms of art had the closest connection, and they depend on each other mutually until today.

Dance needs music as the auxiliary means. Dance art expresses language, presents objects and describes the process of the development of things in the whole process of limb movement. Dance language can clearly describe the plot of the whole event, but hardly express the environment and background of the times. However, precisely it can be achieved by music in the way of auditory. Music can make up the loopholes on the art of dance at this point by utilizing the auditory feature to supplement the defects of concept in the performance of dance. In music creation and performance, the creator always leave emotional expression of times and music characteristic and the application of music in dance creation and performance, and the sense of times will bring feelings of appreciation of the same age to appreciators of different times. 


\section{The application of music in dance creation and performance}

The function of music in dance: Dance needs the music emotion. Excitation and enhancement of action; Dance creation should be carried out according to the music; Music can inspire the desire of dance.

Music can inspire the research and development of techniques in dance creation. In music, the motivation is the smallest structural unit with themes of identity and motivation must be composed of at least one meter and a remake. The motivation itself is not complete, because a melody or a theme is often composed of several motives. Motives in a melody are composed of a dominant motive and several deputy motives. There are also leading motivation and vice- motivation in symphonic dance. At this point the dance and music creation techniques complement each other. This kind of creation form or technique of dance and music is known as "symphonic choreography method" also widely used in dance creation. "Symphonic choreography method" is a kind of dance choreographer method striving to achieve the high unity of music and dance. Firstly, the dance must have the essential emotional factor in the process of the music. Secondly, "Symphonic choreography method" implies that the dance creation must reach a certain depth of thought as symphony, and never to imitate the music structure mechanically for "pure" action combined dance. Next, "Symphonic choreography method" is just one kind of choreographies, and it can not exclude or replace other methods of creation. "Symphonic choreography method" was inspired by the experience of symphony creation, learned from the logic thinking of symphony, greatly enriched the techniques of dance creation, strengthen the expressiveness of dance, and push the dance art to a higher stage.

\section{The choice of music in the dance art}

Music should be consistent with the theme of the dance performance. The relationship between music and dance is from the two senses. One is that it goes into the dance as a factor of time becomes a part of the art of dance, rather than external object. Another is about the cooperation of the two sister arts. In the dance body, time or rhythm and melody are the most important factors of the music art, but they are not the most important core factors in the dance art. Dancers often pay more attention to the dance vocabulary- human action-the "force" factor of human action. This is the most important core factor in the ontology, because there is no dance art without this core factor. Martin John, the famous theorist, once said, "As scenery is the background of the dance, music is its time background, that's all."

Although music does not occupy dominant position in the dance art, dancers, especially cultivated and accomplished dancers have a special sensitivity to music. But the dancer's sensitive which is a special association producing dynamic and emotion, by no means can be equal to the musicians' creative psychology. So it's impossible to ask the dancers to understand the music as well as the musicians. When choreographer chooses music, firstly he must know what kind of music they need, and then selects the musical melody and emotional rendering capabilities. This is a step and principle with which director chooses dance music firstly, then dance creation. Instead, if the choreography is firstly determined the theme of dance, then for the choice of music requires dance creators to pay more attention, have the knowledge of reading music works and make a choice after reading the musical works. Choose music consistent with the theme and the emotional points of the dance performance to match the dance. 
In fact, dance and music theses two art have a broad, respective deduction. The art does not advocate meeting the needs of one by cutting another artistic element, but finding a better conjunction to achieve the fusion of the two. The mutual promotion and complement of the two forms in the practice of art can make music and dance present perfectly on the stage at the same time.

The music shoulder task of presenting and showing the pilot in the dance and ballet. Fundamentally speaking, the close relationship between dance and music is that dance needs music. Because in most cases dance is shown on the accompaniment of music, and the music helps the dance to express its theme. Dance and music exist together, and there is no dance not accompanied by music. The original dance also has a beat knocked or the song to accompany. As the article "Le Le" said: "the poem is used to express the ambition, song is used to express the aspiration, dance is used to express the manners, and three of this all come from the heart, the musical instrument followed". Mao's poetry in the Han dynasty also tells the truth: Poem is ambition in the heart, and it is poetry when expressed. Emotions are expressed by language inevitably when the heart is touched. When the language is not enough to express, people will sigh. When sign is not enough to express, people will sing long song. When the sound of singing is not enough to express, people can't help dancing. The dance even has such saying: "the dance is the visual presentation of music, and the echo of the flow music." Gripskazak Knoff, a famous ballet choreographer and dance theorist in the former Soviet Union also said: "Music"- the soul of dance. Music includes and decides the structure, features and temperament of the dance."

The virtual nature of dance and music makes them both have broad deduction. For the same song, some people think that it is cheerful while others think it is urgent. Although the understanding of the music is different, but the feeling the essence of music is the same. The same body language in dance with the same aesthetic art form has a two completely different dance meaning and different dance vocabulary in different situations. Dancers can give different characters with the same action, and the difference between them is the overall feeling.

The language of music in the structure of the dance works. The dance movement is the language of the dance art, the more expressive language in the dance art is the dance structure. The structure of dance also limits and promotes the appreciation and interpretation of the dance creation and the structure is the skeleton of the dance works, the main technology to support the dance, and the premise of the initiative of the dance movement. Mr. Wu zuqiang in the music structure of dance and other said: "the task of music and dance to make efforts jointly to display content planed to demonstrate by shaping distinctive and convictive images. From the total aspect, the biggest characteristic of the dance music is to help shape and establish dance image, enrich the dance image and strengthen the appeal of the dance image." As the music of the folk dance of the "stone women", depicting the typical character of female in Huian including industry, plain and humiliation with a strong local color of Fujian, and the tone of freedom and simplicity, it is memorable.

The combination of dance and music forms a complete dance art. The movements and postures presented by dance are the most beautiful and touching movements and postures in the world. When combined with music art which has the most beautiful melody and voice, it brings a wonderful enjoyment of art, and produces social function, which is a kind of "Good combination".

Due to the similar nature of music and dance, the dancer has a special liking for music. They always thought that they were not dancing, but dancing music. However, in the contemporary school of modern dance, "Isadora Duncan", mother of modern dance, thought that she promoted dance art 
above the performance of the music. She thought that "dancing is the visual embodiment of music", but a lot of musicians said that she didn't understand music at that time. The performance of dance art needs a kind of rhythm, whether in music, or in the dance, and even the body of the dancer. Followed by the presentation of music melody, music melody is a kind of beautiful embodiment changing the different levels, height, strength and urgency in the fixed rhythm of music...... The melody of the music itself will present a sense of image or a theme of thought. When the music is applied to the dance, it needs consistence between dance creation and the emotion that the music presents. Their relationship of mutual coordination also can help each other to stimulate the inspiration of creation.

The interpretation of dance works to music. "Communication" is the dialogue between language of dance and music notes, -- back and force two times form the form of Dialogue. Although as music shows in practice that the language of music, the combination of rhythm and melody, tends to abstract, it is a form of the exchange of ideas between the author and his direct requester for music. It can not be better that composer can understand the requirements of direct requesters and his talent, which requires them to be understand without speaking a word, and can make the direct requesters satisfactory and full of wisdom and honesty. This is the first point of Chunter Mitter's the basic principle of music. The dance creation needs to achieve this point understanding the music and the creation background, thus achieving the awareness of music.

Generally speaking, the new composing techniques are not a very simple cultural phenomenon since the 20th century. The difference of claims among various schools is very obvious, but their fundamental starting point is to strive for innovation, and strive to go across the road people has never passed before.

In the dance community in recent years, more and more people create dance works by using famous, age-old, previous music. Because in modern society, people emphasis on the concept of innovation increasingly, a $\mathrm{d}$ also more and more people began to interpret the previous music with their own understandings, such as Swan Lake. In ballet dominated by women, modern dance choreographer change woman's world to man's world. The man version of the "Swan Lake" interprets a different story with the same music of Tchaikovsky, interpreting the music works completely.

\section{Conclusions}

Some people say: "music is the soul of dance", which perhaps emphasis on the "music" too much; but it is true that dance can not be separated from the music as the art of both time and space. Music create auditory image by the virtue of sound, while dance create visual image by body., The form of dance art composed of time and space appears when integrated the two, so dance is no longer exist without music in a broadest sense.

In the close relationship between the music art and the dance art, the most closely linked is the rhythm of the dance and the elements that exist in the music art- "rhythm". Different rhythms constitute a variety of dance and music works and highlight different ideas and emotions, so "Rhythm is the basis for expressing affection of people",and dance will be difficult to present without rhythm. This is also the most important key point where music art always exists in the dance art and merges it. 


\section{Acknowledgments}

The research project of Humanities and Social Sciences in Jiangxi Province: The inheritance and development of the living culture -- a study of folk dance in Fuzhou Project number: YS1421

\section{References}

[1](Ming dynasty) written by Zhu Zaiyu noted by Feng Wenci, New Theory of Law, People's music press September 1986

[2]Cai Zhongde, The history of Chinese Musical Aesthetics, People's music press, 1995

[3]Written by Institute of music of the Ministry of culture and institute of literature and Arts, theory of ancient music in China, People's music press, 1983

[4]Tian Qing, The history of ancient music in China, Shanghai literature and Art Press, 1984

[5] Written by Han Ping, DuLei, Course in Folk Dance of Chinese Minority, Higher Education Press, 2004

[6] Written by Zhou Ping, Huang Yihua, The arrangement of teaching of Folk dance in China, Higher Education Press, 2004

[7] Written by Wang Wei, The basic training course of Chinese classical dance, Higher Education Press, 2004

[8]Wang Mei, Teaching notes of Choreographer, Journal of Beijing Dance Academy Selected papers, 1999

[9]Luo Xiongyan, The theory and operation of "dynamic cut method", Journal of Beijing Dance Academy Selected papers, 2004

[10]Liu Jian, The expansion of thought to body, Journal of Beijing Dance Academy Selected papers, 2004 